\title{
A crossover study of the combination therapy of metformin and exenatide or biphasic insulin aspart 30 in overweight or obese patients newly diagnosed with type 2 diabetes mellitus
}

\author{
HUIBIAO QUAN, HUACHUAN ZHANG, WEIPING WEI, TUANYU FANG, DAOXIONG CHEN and KAINING CHEN \\ Department of Endocrinology, People's Hospital of Hainan, Haikou, Hainan 570311, P.R. China
}

Received October 19, 2015; Accepted November 18, 2016

DOI: $10.3892 /$ etm.2017.4863

\begin{abstract}
The aim of the present study was to explore the effects of various combinations of exenatide, metformin (MET) and biphasic insulin aspart 30 (BIA30) on type 2 diabetes mellitus (T2DM). Two hundred overweight or obese patients newly diagnosed with T2DM were evenly randomized into two groups: A (twice daily for all: Phase I, $5 \mu \mathrm{g}$ exenatide $+0.5 \mathrm{~g}$ MET for 4 weeks, then $10 \mu \mathrm{g}$ exenatide $+0.5 \mathrm{~g}$ MET for 8 weeks; Phase II, 0.5 g MET for 12 weeks; Phase III, 0.3-0.4 U/kg/day BIA30 + $0.5 \mathrm{~g}$ MET for 12 weeks) and B (Phases I, II, III matched the phases III, II and I in group A). In groups A and $\mathrm{B}$ a significant decrease and increase, respectively, in glycated hemoglobin (HbAlc) and body mass index (BMI) was noted during Phase I. A $3.2 \pm 0.4-\mathrm{kg}$ decrease in body weight in group A and a $2.6 \pm 0.3-\mathrm{kg}$ increase in group B was observed. In Phase II, HbAlc was significantly increased in both groups $(\mathrm{P}<0.05)$. In Phase III, the BMI was increased in group A and reduced in group $\mathrm{B}(\mathrm{P}<0.05)$. There was a $3.8 \pm 0.4-\mathrm{kg}$ weight decrease in group B and 4.2 $\pm 0.5-\mathrm{kg}$ increase in group A $(\mathrm{P}<0.05)$. The combination of exenatide and MET promoted weight loss, glycemic control, $\beta$-cell function index, $\mathrm{C}$ peptide and adiponectin levels. These results suggested that the combination of exenatide and MET is better than the combination of BIA and MET for the therapy of overweight or obese patients newly diagnosed with T2DM.
\end{abstract}

\section{Introduction}

Type 2 diabetes mellitus (T2DM) is a chronic metabolic disease affecting $>220$ million individuals worldwide (1). Numerous antidiabetic drugs have been developed to treat T2DM according to the pathogenesis in individual patients. Glucagon-like peptide 1 (GLP-1) is a gut-derived incretion

Correspondence to: Dr Huibiao Quan, Department of Endocrinology, People's Hospital of Hainan, No. 4 Building, 19 Xiuhua Road, Haikou, Hainan 570311, P.R. China

E-mail: huibiaohn@163.com

Key words: biphasic insulin aspart, exenatide, metformin, combination therapy, overweight, obesity, type 2 diabetes mellitus that stimulates insulin and suppresses glucagon secretion, inhibits gastric emptying and $\beta$-cell apoptosis, and reduces appetite and food intake (2-4). GLP-1 has been proposed for the treatment of T2DM patients; however, native GLP-1 can be degraded within 2-3 min (4). The development of GLP-1 receptor agonists resistant to this degradation is therefore necessary (5). Exenatide, a short-acting GLP-1 receptor agonist that improves insulin secretion and increases $\beta$-cell mass, is a potential drug for T2DM treatment (6). Furthermore, exenatide improves glycemic control and weight loss $(7,8)$. Although the antidiabetic activity of exenatide has been widely reported (9-11), a combined therapy promotes insulin secretion and insulin sensitivity in new-onset T2DM patients to produce a greater, more durable reduction in glycated haemoglobin (HbA1c) levels compared with mono-therapy (12).

Biphasic insulin aspart 30 (BIA30) is man-made insulin and improves glycemic control in T2DM patients in whom the condition is poorly controlled by other medications (13). In a previous study, a larger proportion of patients with T2DM achieved glycemic goals when treated with BIA30 than when treated with exenatide (14). Furthermore, the insulin-treated groups had an increased incidence of minor hypoglycemic events and weight gain. BIA30 was found to be more effective in the treatment of patients with a high baseline HbA1c level, enabling most patients to achieve glycemic control (14). BIA30 has additionally been shown to improve glycemic control subsequent to the failure of diet, exercise and oral antidiabetic agents (15); however, the side effects of the drug are evident and BIA30 therapy can increase the risk of daytime hypoglycemia (16).

Metformin (MET) is an oral antidiabetic drug and the first-line agent for the treatment of T2DM, particularly in overweight and obese individuals (17); however, MET-treated patients are known to experience a progressive deterioration in glycemic control. Furthermore, evidence has shown that the modification of $\beta$-cell deterioration by MET is limited (18).

The use of a combination therapy may enhance the efficacy of glycemic and weight control in overweight or obese patients. The combination of exenatide and MET has been shown to promote weight loss and glycemic control, and to increase $\mathrm{C}$-peptide levels, $\beta$-cell function index and adiponectin levels (19). However, the effectiveness of the combination remains to be elucidated in overweight or obese patients with newly diagnosed type 2 diabetes mellitus. MET 
and BIA30 may reduce $\mathrm{HbA}$ (1c) and mean prandial plasma glucose increment to a greater extent in diabetic patients when compared with the patients treated with insulin glargine plus glimepiride (20). To the best of our knowledge, the efficacy of a combination therapy of MET and BIA30 has not yet been reported in specifically obese patients, only in general diabetic patients, and the efficacy and safety of the two combination therapies (exenatide or BIA30 and MET) in treating T2DM have not been previously compared, which was the purpose of the present study.

\section{Materials and methods}

Participants. All patients were enrolled at Department of Endocrinology, People's Hospital of Hainan Province (Haikou, China) between May 2011-June 2014 and written informed consent was obtained for inclusion of their data in the study. A total of 480 T2DM patients (144 male/336 female) were screened. Two hundred patients took part in present study following analysis of inclusion and exclusion criteria. The clinical protocol of the study was approved by the Institutional Review Board of the People's Hospital of Hainan Province (Haikou, China) and all steps confirmed to the principles described in the World Medical Association Declaration of Helsinki (21). The inclusion criteria for the present study were i) T2DM newly diagnosed within three months; ii) a HbAlc level of $\leq 10.5 \%$; iii) a body mass index (BMI) of $>24$ and $<40 \mathrm{~kg} / \mathrm{m}^{2}$; iv) a stable weight for $\geq 3$ months prior to the study; and v) no clinically significant abnormal findings. The subjects would be excluded if they i) had experienced more than three episodes of severe hypoglycemia within the 6 months before screening; ii) had used any prescription drug to obtain weight loss within the 3 months preceding the study; or iii) had a family history of T2DM.

Clinical variables and validation. The BMI was calculated by dividing weight $(\mathrm{kg})$ by the square of height $\left(\mathrm{m}^{2}\right)$. The main questionnaire requested that the waists and hips of the patients were measured at the point of greatest circumference while the participants stood in a relaxed stance. Self-reported weight has been shown to be valid in this cohort if his or her spouse gave a similar report. Certain factors, including age, gender, drinking and smoking status, BMI and hypertension, were taken into consideration to reduce multiple factors interfering with the results of the groups. Furthermore, all the subjects were from the city of Haikou and were of a similar socio-economic background. Subsequent to analyzing the answers of the survey, 200 cases were considered to meet the selection criteria. Two hundred overweight or obese patients with newly diagnosed T2DM patients were randomized and evenly assigned to two groups ( $\mathrm{n}=100$ for each group): Group A (Phase I, $5-\mu \mathrm{g}$ exenatide $+0.5 \mathrm{~g}$ MET twice daily for 4 weeks, then $10 \mu \mathrm{g}$ exenatide $+0.5 \mathrm{~g}$ MET twice daily for 8 weeks; Phase II, $0.5 \mathrm{~g}$ MET twice daily for 12 weeks; Phase III, 0.3-0.4 U/kg/day BIA30 + 0.5 g MET twice daily for 12 weeks) and group B (Phases I, II and III matched the phases III, II and I in group A, respectively) (Fig. 1).

Biochemical analysis. Subsequent to obtaining informed consent, all patients were subjected to analysis of capillary whole blood glucose $(\mathrm{CG})$ levels. The participants with a random CG level of $>5.6 \mathrm{mM}$ were considered to be at an elevated risk of diabetes (22) and received insulin as a further therapy, as a single treatment is unable to control the progression of T2DM. The levels of glucose and HbAlc were measured $2 \mathrm{~h}$ after a 75 -g oral glucose load. The participants received no formal dietary preparation. Serum glucose levels were determined using a glucose oxidase method via a dry chemistry analyzer (Ningbo Scientz Biotechnology Co., Ltd., Ningbo, China). HbAlc levels were determined via affinity chromatography (GE Healthcare, Piscataway, NJ, USA). Levels of high-density lipoprotein (HDL)-cholesterol were assessed using a commercial kit (Boehringer Ingelheim $\mathrm{GmbH}$, Mannheim, Germany), and levels of low-density lipoprotein (LDL)-cholesterol were measured using the formula proposed by Friedwald et al (23). Triglyceride levels were measured using a colorimetric method involving lipoprotein lipase and glycerol kinase (Bayer RA-1000 triglyceride kit; Bayer AG, Leverkusen, Germany). The serum insulin concentration was tested via ELISA (Abnova Corp., Walnut, CA, USA). Triglyceride levels were measured using enzyme colorimetry. Basal blood glucose (BG) and fasting blood glucose (FBG) levels were automatically analyzed on an automatic random access biochemistry analyzer (Hitachi 917; Hitachi, Ltd., Tokyo, Japan). Serum levels of basal insulin (BINS) and fasting insulin (FINS) were measured using radioimmunoassays (Tongji Hospital, Shanghai, China). All measurements were performed in triplicate. The homeostatic model assessment of estimated insulin resistance (HOMA-IR) index was calculated using the following formula: HOMA-IR=FBGxFINS/22.5. The HOMA of estimated insulin secretory function (HOMA-IS) was calculated using the equation HOMA-IS=20xFINS/(FBG-3.5). The HOMA of $\beta$-cell function (HOMA-B) index was calculated using the equation HOMA-B=20xBINS/(BG-3.5).

ELISA analysis. Human ELISA kits for C-reactive protein (CRP; cat. no. ab99995; sensitivity <2 pg/ml; the Stop Solution alters the color from blue to yellow and the intensity of the color is measured at a wavelength of $450 \mathrm{~nm}$ ), tumor necrosis factor- $\alpha$ (TNF- $\alpha$; cat. no. ab46087; sensitivity $<10$ pg/ml), adiponectin (cat. no. ab99968; sensitivity $<25 \mathrm{pg} / \mathrm{ml}$; the Stop Solution alters the color from blue to yellow and the intensity of the color is measured at a wavelength of $450 \mathrm{~nm}$ ) and resistin (cat. no. ab100634; sensitivity $<2 \mathrm{pg} / \mathrm{ml}$; the Stop Solution alters the color from blue to yellow and the intensity of the color is measured at a wavelength of $450 \mathrm{~nm}$ ) were purchased from Abcam Ltd. (Cambridge, MA, USA). All cell factors were also measured with the aforementioned ELISA kits.

Statistical analysis. A Chi Square test and a paired samples Student's $t$-test were conducted to compare the difference between two sets of quantitative data from two groups. The analysis was conducted using SPSS software version 20.0 (IBM SPSS, Armonk, NY, USA). The treatment effects were assessed at a two-sided significance level of 0.05 . Fisher's exact tests were used for comparisons based on categorical variables (e.g. biochemical index, weight loss, glycemic control, $\beta$-cell function index, $C$ peptide and adiponectin levels). Predefined analyses were performed to determine the effect of the baseline status on changes in HbAlc and FBG levels. Two analyses 


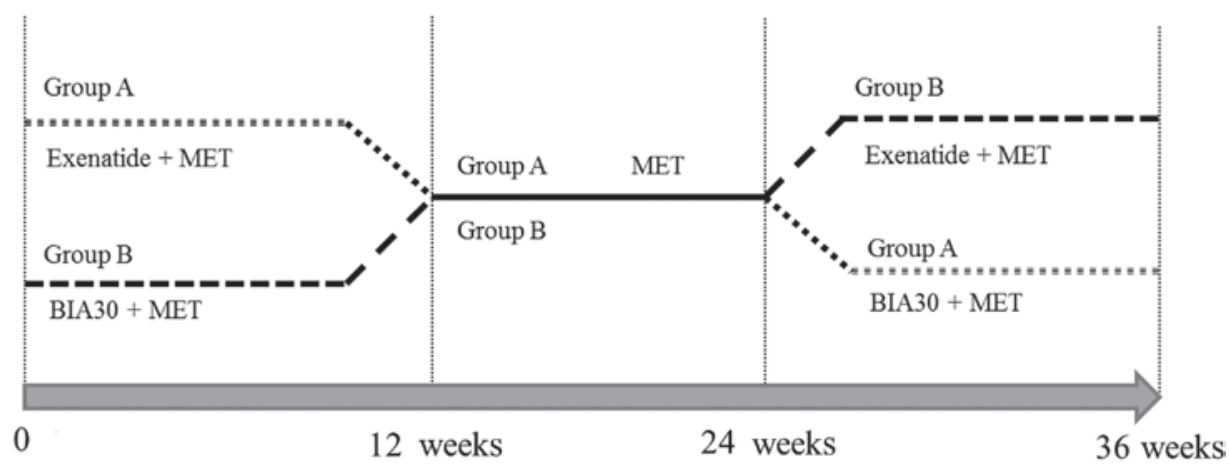

Figure 1. Flowchart of the study. Group A ( $\mathrm{n}=100 ; 5 \mu \mathrm{g}$ exenatide $+0.5 \mathrm{~g}$ MET twice daily for 4 weeks, then $10 \mu \mathrm{g}$ exenatide $+0.5 \mathrm{~g}$ MET twice daily for 8 weeks; then only $0.5 \mathrm{~g}$ MET twice daily for 12 weeks; thereafter, 0.3-0.4 U/kg/day BIA30 +0.5 g MET twice daily for 12 weeks) and Group B (n=100; 0.3-0.4 U/kg/day BIA30 +0.5 $\mu \mathrm{g}$ MET twice daily for 12 weeks; then only $0.5 \mathrm{~g}$ MET twice daily for 12 weeks; thereafter, $5 \mu \mathrm{g}$ exenatide $+0.5 \mathrm{~g}$ MET twice daily for 12 weeks). MET, metformin, BIA30, biphasic insulin aspart 30

(associations between weight loss and adiponectin, resistin, TNF $\alpha$, and CRP levels) were added to the statistical plan (post hoc). Values are expressed as the mean \pm standard error of the mean.

\section{Results}

Baseline characteristics of overweight or obese patients with newly diagnosed T2DM. At the end of the run-in period, 200 patients were randomly divided into the two cross-over groups (Fig. 1). Table I shows the baseline characteristics of the patients. The mean age of the participants was $59 \pm 9.2$ years (range, 48-68 years). The cohort comprised 81 male and 119 female patients (female/male ratio, 3:2). No significant differences in the baseline demographic and metabolic characteristics of the patients were present between Groups A and $\mathrm{B}(\mathrm{P}>0.05)$.

Exenatide + MET is more efficacious than MET + BIA30 for overweight or obese patients with T2DM in Phase I. The change in body weight during Phase I is shown in Table II. Exenatide + MET combination therapy demonstrated superiority to MET + BIA30 regarding the change in body weight. The patients in Group A exhibited significant reductions in body weight from baseline to week $12(\mathrm{P}<0.01)$ (Table II), with a mean weight decrease of $3.2 \pm 0.4-\mathrm{kg}$ in Group A and mean weight increase of $2.6 \pm 0.3-\mathrm{kg}$ in Group B (Table II). Consistently, the patients in Group A and B exhibited a significant decrease and increase, respectively, in the BMI from baseline to week $12(\mathrm{P}<0.01)$ (Table II).

The changes in HbAlc levels after the 12-week trial are shown in Table II. The two groups exhibited significant reductions in the HbA1c levels at week 12 vs. the levels at the baseline $(\mathrm{P}<0.01)$. There was a statistically significant difference regarding the changes between groups $\mathrm{A}$ and $\mathrm{B}(\mathrm{HbA} 1 \mathrm{c}$ changes of $-1.8 \pm 0.5$ and $-1.3 \pm 0.6 \%$, respectively) $(\mathrm{P}<0.01)$.

After the 12-week trial with the combination therapy, the patients in groups A and B had significantly lower mean fasting glucose levels $(\mathrm{P}<0.01)$, and 2-h post-prandial glucose levels $(\mathrm{P}<0.01$; Table II). The patients in groups $\mathrm{A}$ and $\mathrm{B}$ had no significant changes in fasting c peptide and 2-h postprandial c peptide $(\mathrm{P}>0.05)$ (Table II). However, significant decreases in resistin, CRP, TNF- $\alpha$ and insulin resistance were observed in group $\mathrm{A}(\mathrm{P}<0.05)$, and also in group $\mathrm{B}$ with the exception of resistin (Table II). In group $\mathrm{A}$, significant increases in insulin sensitivity and adiponectin were present $(\mathrm{P}<0.05)$, and insulin sensitivity was increased in group $\mathrm{B}(\mathrm{P}<0.05)$. Regarding lipid profiles, significant decreases in triglycerides (TG), total cholesterol (TC) and LDL and an increase in HDL were observed in group A $(\mathrm{P}<0.05)$ (Table II). In group $\mathrm{B}$, significant decreases in TG $(\mathrm{P}<0.01)$ and no changes in $\mathrm{TC}, \mathrm{HDL}$ and LDL were observed ( $\mathrm{P}>0.05)$ (Table II).

Met monotherapy has similar effects in Groups $A$ and $B$ in Phase II. As shown in Table III, no statistically significant change in body weight was identified in Phase II in groups A and $\mathrm{B}(\mathrm{P}>0.05)$. However, the two groups exhibited significant increases in HbA1c levels at week 24 compared to those at week $12(\mathrm{P}<0.01)$. The increase in HbAlc in group B was significantly higher compared to that in group A $(1.7 \pm 0.8$ and $1.0 \pm 0.2 \%$, respectively) $(\mathrm{P}<0.01)$.

Compared with the levels at 12 weeks, the patients in groups A and B had significantly higher mean fasting glucose levels $(\mathrm{P}<0.01)$ and 2 -h post-prandial glucose levels at 24 weeks $(\mathrm{P}<0.01)$ (Table III). No significant changes in fasting c peptide and 2-h post-prandial c peptide were detected in either group ( $\mathrm{P}>0.05)$ (Table III), and furthermore, body weight, adiponectin, resistin and CRP showed no significant changes within each group $(\mathrm{P}>0.05)$. Significant increases in TNF- $\alpha$ and decreases in insulin resistance and sensitivity were detected in each group $(\mathrm{P}<0.05)$. None of the groups had significant changes in BMI, TC, HDL and LDL during Phase II $(\mathrm{P}>0.05)$, while a significant increase in TG was observed in Group B $(\mathrm{P}<0.01)$, but not in Group A (Table III).

Exenatide + MET is more efficacious than MET + BIA30 regarding body weight and glycemic control in Phase III. As shown in Table IV, exenatide + MET combination therapy (Group B) demonstrated superiority to MET + BIA30 (Group A) regarding changes in body weight. The patients in Group B exhibited significant reductions in body weight from week 24 to $36(\mathrm{P}<0.01)$, with a mean weight decrease of $3.8 \pm 0.4 \mathrm{~kg}$ in group B and a mean weight increase of $4.2 \pm 0.5 \mathrm{~kg}$ in Group A (Table IV). Consistently, the patients in Group B and A exhibited significant decreases and increases, respectively, in the BMI from week 24 to $36(\mathrm{P}<0.01)$ (Table IV). 
Table I. Baseline demographic and metabolic characteristics of the patients.

\begin{tabular}{|c|c|c|c|c|}
\hline Characteristic & Group A & Group B & $t / \chi^{2}$ & P-value \\
\hline Age (years) & $58.1 \pm 10.2$ & $57.4 \pm 9.2$ & 0.18 & $0.86^{\mathrm{a}}$ \\
\hline Gender, male, n (\%) & $40(40)$ & $41(41)$ & 0.16 & $0.69^{\mathrm{b}}$ \\
\hline Smoker/non-smoker & $28 / 72$ & $30 / 70$ & 0.10 & $0.76^{\mathrm{b}}$ \\
\hline Drinker/non-drinker & $36 / 64$ & $38 / 62$ & 0.09 & $0.77^{b}$ \\
\hline \multicolumn{5}{|l|}{ Ethnicity (\%) } \\
\hline HANZHU & 80 & 82 & 0.13 & $0.72^{b}$ \\
\hline MANCHU & 12 & 10 & - & - \\
\hline MONGOLIAN & 6 & 4 & - & - \\
\hline TIBETAN & 2 & 4 & - & - \\
\hline Weight (kg) & $81 \pm 16$ & $82 \pm 17$ & 0.19 & $0.85^{\mathrm{a}}$ \\
\hline BMI $\left(\mathrm{kg} / \mathrm{m}^{2}\right)$ & $27.3 \pm 2.4$ & $28.1 \pm 2.1$ & 0.82 & $0.43^{\mathrm{a}}$ \\
\hline HbA1c $(\%)$ & $8.6 \pm 1.2$ & $8.8 \pm 1.3$ & 0.89 & $0.40^{\mathrm{a}}$ \\
\hline FBG (mmol/l) & $8.7 \pm 1.3$ & $8.9 \pm 1.2$ & 0.58 & $0.29^{\mathrm{a}}$ \\
\hline 2hPG (mmol/l) & $13.6 \pm 2.1$ & $14.3 \pm 3.1$ & 0.78 & $0.24^{\mathrm{a}}$ \\
\hline $\mathrm{TG}(\mathrm{mmol} / \mathrm{l})$ & $2.6 \pm 1.3$ & $2.8 \pm 1.6$ & 0.19 & $0.84^{\mathrm{a}}$ \\
\hline $\mathrm{TC}(\mathrm{mmol} / \mathrm{l})$ & $5.6 \pm 1.1$ & $5.9 \pm 0.5$ & 0.25 & $0.40^{\mathrm{a}}$ \\
\hline HDL (mmol/l) & $1.3 \pm 0.2$ & $1.5 \pm 0.6$ & 0.15 & $0.86^{\mathrm{a}}$ \\
\hline LDL cholesterol (mmol/l) & $3.8 \pm 1.1$ & $4.2 \pm 1.3$ & 0.08 & $0.98^{\mathrm{a}}$ \\
\hline Resistin (ng/ml) & $14.29 \pm 4.21$ & $14.13 \pm 3.76$ & 1.22 & $0.14^{\mathrm{a}}$ \\
\hline Adiponcetin (pg/ml) & $151.47 \pm 44.1$ & $146.21 \pm 36.1$ & 1.81 & $0.06^{\mathrm{a}}$ \\
\hline CRP (ug/ml) & $5.63 \pm 1.54$ & $5.78 \pm 1.34$ & 0.17 & $0.43^{\mathrm{a}}$ \\
\hline $\mathrm{TNF} \alpha(\mathrm{pg} / \mathrm{ml})$ & $380.62 \pm 110.1$ & $388.79 \pm 92.3$ & 0.30 & $0.38^{\mathrm{a}}$ \\
\hline HOMA-IR & $6.42 \pm 3.23$ & $6.67 \pm 3.45$ & 1.97 & $0.06^{\mathrm{a}}$ \\
\hline HOMA-IS & $67.14 \pm 36.4$ & $66.34 \pm 27.1$ & 1.22 & $0.14^{\mathrm{a}}$ \\
\hline Duration of diabetes (years) & $0.8 \pm 0.4$ & $0.7 \pm 0.5$ & 0.19 & $0.42^{\mathrm{a}}$ \\
\hline \multicolumn{5}{|l|}{$\mathrm{HR}$, beats/min } \\
\hline 24-h & $75.2 \pm 12.4$ & $74.2 \pm 13.3$ & 0.88 & $0.40^{\mathrm{a}}$ \\
\hline Daytime & $79.8 \pm 13.1$ & $79.2 \pm 12.1$ & 0.18 & $0.86^{\mathrm{a}}$ \\
\hline Nighttime & $71.5 \pm 11.9$ & $70.5 \pm 12.4$ & 0.67 & $0.52^{\mathrm{a}}$ \\
\hline \multicolumn{5}{|l|}{$\mathrm{SBP}, \mathrm{mm} \mathrm{Hg}$} \\
\hline $24-\mathrm{h}$ & $39.4 \pm 13.9$ & $138.6 \pm 12.9$ & 2.19 & $0.07^{\mathrm{a}}$ \\
\hline Daytime & $144.1 \pm 14.2$ & $145.3 \pm 14.7$ & 1.28 & $0.25^{\mathrm{a}}$ \\
\hline Nighttime1 & $135.7 \pm 13.5$ & $136.7 \pm 14.1$ & 1.05 & $0.37^{\mathrm{a}}$ \\
\hline \multicolumn{5}{|l|}{$\mathrm{DBP}, \mathrm{mm} \mathrm{Hg}$} \\
\hline $24-\mathrm{h}$ & $83.1 \pm 7.4$ & $83.9 \pm 7.6$ & 0.11 & $0.92^{\mathrm{a}}$ \\
\hline Daytime & $86.3 \pm 7.7$ & $86.8 \pm 7.9$ & 0.09 & $0.96^{\mathrm{a}}$ \\
\hline Nighttime & $80.0 \pm 7.5$ & $80.8 \pm 7.8$ & 0.20 & $0.85^{\mathrm{a}}$ \\
\hline
\end{tabular}

${ }^{\mathrm{a}} t$-test; ${ }^{\mathrm{b}} \mathrm{chi}$-square test. Values are expressed as the mean \pm standard error of the mean or as $\mathrm{n}(\%)$ as applicable. BMI, body mass index; HbA1c, glycated hemoglobin; FBG, fasting blood glucose; 2hPG, 2-h post-prandial plasma glucose; TG, triglycerides; TC, total cholesterol; HDL, high-density lipoprotein; CRP, C-reactive protein; TNF, tumor necrosis factor; HOMA, homeostatic model assessment; IR, insulin resistance; IS, insulin sensitivity; HR, heart rate; SBP, systolic blood pressure; DBP, diastolic blood pressure. Values are expressed as the mean \pm standard error of the mean.

The changes in HbA1c levels from week 24 to 36 are shown in Table IV. The two groups exhibited significant reductions in HbA1c levels at week 36 vs. those at week $24(\mathrm{P}<0.01)$. A statistically significant difference in the changes of $\mathrm{HbAlc}$ between groups $\mathrm{A}$ and $\mathrm{B}$ was present $(-1.2 \pm 0.2$ and $-1.8 \pm 0.6 \%$, respectively; $\mathrm{P}<0.01)$. Thus, exenatide + MET demonstrated a better control for HbA1c levels.
Compared with those at week 24, the patients in Groups $\mathrm{A}$ and $\mathrm{B}$ had significantly lower mean fasting glucose $(\mathrm{P}<0.01)$ and 2 -h post-prandial glucose levels at week 36 $(\mathrm{P}<0.01)$ (Table IV). However, none of the groups showed any significant changes in fasting c peptide and 2-h post-prandial c peptide ( $\mathrm{P}>0.05)$ (Table IV). Furthermore, significant decreases in resistin, CRP, TNF- $\alpha$ and insulin resistance 
Table II. Parameter changes in groups A and B in phase I.

\begin{tabular}{|c|c|c|c|c|c|c|}
\hline \multirow[b]{2}{*}{ Parameter } & \multicolumn{3}{|c|}{ Group A } & \multicolumn{3}{|c|}{ Group B } \\
\hline & Baseline & 12 weeks & P-value & Baseline & 12 weeks & P-value \\
\hline Waist circumference $(\mathrm{cm})$ & $109.6 \pm 14.2$ & $96.7 \pm 14.3$ & 0.006 & $107.3 \pm 12.5$ & $110.7 \pm 14.8$ & 0.046 \\
\hline Weight $(\mathrm{kg})$ & $81 \pm 16$ & $78 \pm 16$ & 0.019 & $82 \pm 17$ & $85 \pm 17$ & 0.042 \\
\hline FBG (mmol/l) & $8.7 \pm 1.3$ & $7.0 \pm 1.0$ & 0.002 & $8.9 \pm 1.2$ & $6.9 \pm 1.1$ & 0.019 \\
\hline 2hPG (mmol/l) & $13.6 \pm 2.1$ & $10.5 \pm 1.9$ & 0.001 & $14.3 \pm 3.1$ & $10.3 \pm 1.4$ & 0.001 \\
\hline HbAlc $(\%)$ & $8.6 \pm 1.2$ & $6.8 \pm 0.7$ & 0.001 & $8.8 \pm 1.3$ & $6.5 \pm 0.6$ & 0.001 \\
\hline BMI $\left(\mathrm{kg} / \mathrm{m}^{2}\right)$ & $27.3 \pm 2.4$ & $24.5 \pm 2.1$ & 0.001 & $28.1 \pm 2.1$ & $30.5 \pm 1.2$ & 0.031 \\
\hline TG $(\mathrm{mmol} / \mathrm{l})$ & $2.6 \pm 1.3$ & $1.7 \pm 1.1$ & 0.001 & $2.8 \pm 1.6$ & $1.9 \pm 1.3$ & 0.001 \\
\hline $\mathrm{TC}(\mathrm{mmol} / \mathrm{l})$ & $5.6 \pm 1.1$ & $4.5 \pm 1.4$ & 0.028 & $5.9 \pm 0.5$ & $5.0 \pm 2.3$ & 0.057 \\
\hline HDL (mmol/l) & $1.3 \pm 0.2$ & $1.4 \pm 0.4$ & 0.059 & $1.5 \pm 0.6$ & $1.6 \pm 0.8$ & 0.752 \\
\hline LDL (mmol/l) & $3.8 \pm 1.1$ & $3.3 \pm 1.1$ & 0.043 & $4.2 \pm 1.3$ & $4.0 \pm 1.7$ & 0.463 \\
\hline FINS (pmol/l) & $136.8 \pm 51.6$ & $118.4 \pm 37.9$ & 0.061 & $132.6 \pm 45.7$ & $128.6 \pm 45.9$ & 0.586 \\
\hline HOMA-IR & $6.42 \pm 3.23$ & $4.16 \pm 2.45$ & 0.002 & $6.67 \pm 3.45$ & $6.23 \pm 2.12$ & 0.044 \\
\hline HOMA-IS & $67.14 \pm 36.4$ & $91.65 \pm 43.7$ & 0.001 & $66.34 \pm 27.1$ & $101.34 \pm 54.2$ & 0.001 \\
\hline Fasting c peptide (nmol/l) & $1.14 \pm 0.45$ & $1.12 \pm 0.33$ & 0.751 & $1.21 \pm 0.34$ & $1.54 \pm 0.48$ & 0.025 \\
\hline 2-h postprandial c peptide (nmol/l) & $2.69 \pm 1.43$ & $2.84 \pm 1.25$ & 0.634 & $2.43 \pm 0.32$ & $2.98 \pm 1.14$ & 0.079 \\
\hline \multicolumn{7}{|l|}{ Adiponectin } \\
\hline$(\mathrm{pg} / \mathrm{ml})$ & $151.47 \pm 44.1$ & $172.1 \pm 40.3$ & 0.005 & $146.21 \pm 36.1$ & $148.5 \pm 37.6$ & 0.642 \\
\hline Resistin (ng/ml) & $14.29 \pm 4.21$ & $6.75 \pm 3.14$ & 0.001 & $14.13 \pm 3.76$ & $12.34 \pm 4.65$ & 0.052 \\
\hline $\mathrm{TNF} \alpha(\mathrm{pg} / \mathrm{ml})$ & $380.62 \pm 110.1$ & $280.13 \pm 121.4$ & 0.001 & $388.79 \pm 92.3$ & $312.79 \pm 119.9$ & 0.001 \\
\hline CRP (mg/l) & $5.63 \pm 1.54$ & $4.12 \pm 1.04$ & 0.001 & $5.78 \pm 1.34$ & $5.01 \pm 1.96$ & 0.024 \\
\hline
\end{tabular}

$\mathrm{P}<0.05$ was considered to indicate a statistically significant difference. Values are expressed as the mean \pm standard error of the mean. BMI, body mass index; HbA1c, glycated hemoglobin; FBG, fasting blood glucose; 2hPG, 2-h post-prandial plasma glucose; TG, triglycerides; TC, total cholesterol; H/LDL, high/low-density lipoprotein; CRP, C-reactive protein; TNF, tumor necrosis factor; HOMA, homeostatic model assessment; IR, insulin resistance; IS, insulin sensitivity; FINS, fasting insulin. Values are expressed as the mean \pm standard error of the mean.

were detected in group $\mathrm{B}(\mathrm{P}<0.05)$, as well as in group A with the exception of resistin and CRP $(\mathrm{P}<0.05)$. A 4-kg weight decrease was observed in group B and a 4-kg weight increase in group A. Significant increases in insulin resistance, insulin sensitivity and adiponectin were present in each group $(\mathrm{P}<0.05)$. Regarding lipid profiles, significant decreases in TG, TC and LDL and an increase in HDL was observed in group $\mathrm{B}(\mathrm{P}<0.05)$, while in Group $\mathrm{A}$, a significant decrease in TG $(\mathrm{P}<0.01)$ and no changes in TC, HDL and LDL were noted $(\mathrm{P}>0.05)$ (Table IV).

These cross-over results suggested that the combination of exenatide and MET is superior to the combination of BIA30 and MET for therapy of overweight or obese patients with T2DM.

Combined therapy with exenatide + MET demonstrates superiority to BIA30 + MET for improving the lipid profile in overweight or obese patients. The changes in lipid profiles are shown in Tables II-IV. The results showed that exenatide + MET combination therapy reduced the levels of TG, TC and LDL $(\mathrm{P}<0.05)$, while BIA30 + MET combination therapy did not $(\mathrm{P}>0.05)$. Furthermore, exenatide + MET combination therapy improved HDL levels $(\mathrm{P}<0.05)$, while BIA30 + MET did not significantly affect HDL levels $(\mathrm{P}>0.05)$.
Exenatide + MET therapy shows superiority over $B I A 30+$ MET by decreasing adiponectin, CRP, TNF- $\alpha$ and resistin levels in overweight or obese patients with T2DM. Resistin is a hormone that potentially links obesity to diabetes (24). Levels of resistin are increased in diet-induced and genetic types of obesity, and the administration of anti-resistin antibody improves blood sugar levels and insulin action in mice with diet-induced obesity (24). In the present study, exenatide + MET combination therapy significantly decreased resistin levels $(\mathrm{P}<0.05)$, while BIA30 + MET combination therapy did not. These results suggested that exenatide + MET combination therapy has a superior anti-diabetes effect to that of BIA30 + MET.

Adiponectin, a hormone secreted by fat cells, has insulin-sensitizing and anti-inflammatory properties. Low levels of adiponectin in the plasma have been reported to be associated with insulin resistance, which may cause obesity and diabetes (25). Adiponectin levels in the blood of diabetic patients are lower than those in normal individuals (26). In the present study, the exenatide + MET combination therapy treatment significantly increased adiponectin levels $(\mathrm{P}<0.05)$, while BIA30 + MET did not.

CRP is a protein that can be found in the blood. The levels of CRP increase following the occurrence of inflammation, 
Table III. Parameter changes in groups A and B in phase II.

\begin{tabular}{|c|c|c|c|c|c|c|}
\hline \multirow[b]{2}{*}{ Parameter } & \multicolumn{3}{|c|}{ Group A } & \multicolumn{3}{|c|}{ Group B } \\
\hline & 12 weeks & 24 weeks & P-value & 12 weeks & 24 weeks & P-value \\
\hline Waist circumference $(\mathrm{cm})$ & $96.7 \pm 14.3$ & $96.2 \pm 11.3$ & 0.267 & $110.7 \pm 14.8$ & $111.4 \pm 13.6$ & 0.846 \\
\hline Weight $(\mathrm{kg})$ & $78 \pm 16$ & $78.2 \pm 16.3$ & 0.584 & $85 \pm 17$ & $82.3 \pm 19.6$ & 0.712 \\
\hline FBG (mmol/l) & $7.0 \pm 1.0$ & $7.8 \pm 1.2$ & 0.006 & $6.9 \pm 1.1$ & $7.9 \pm 1.1$ & 0.011 \\
\hline 2hPG (mmol/l) & $10.5 \pm 1.9$ & $12.5 \pm 1.1$ & 0.004 & $10.3 \pm 1.4$ & $14.1 \pm 2.4$ & 0.006 \\
\hline HbAlc $(\%)$ & $6.8 \pm 0.7$ & $7.8 \pm 0.6$ & 0.002 & $6.5 \pm 0.6$ & $8.2 \pm 1.5$ & 0.001 \\
\hline $\operatorname{BMI}\left(\mathrm{kg} / \mathrm{m}^{2}\right)$ & $26.5 \pm 2.1$ & $26.1 \pm 1.9$ & 0.513 & $30.5 \pm 1.2$ & $30.1 \pm 3.1$ & 0.961 \\
\hline $\mathrm{TG}(\mathrm{mmol} / \mathrm{l})$ & $1.7 \pm 1.1$ & $1.82 \pm 1.41$ & 0.218 & $1.9 \pm 1.3$ & $2.6 \pm 1.2$ & 0.001 \\
\hline $\mathrm{TC}(\mathrm{mmol} / \mathrm{l})$ & $4.5 \pm 1.4$ & $5.3 \pm 0.7$ & 0.052 & $5.0 \pm 2.3$ & $5.6 \pm 0.6$ & 0.075 \\
\hline HDL (mmol/l) & $1.4 \pm 0.4$ & $1.36 \pm 0.4$ & 0.064 & $1.6 \pm 0.8$ & $1.7 \pm 0.5$ & 0.062 \\
\hline LDL (mmol/l) & $3.5 \pm 1.1$ & $3.61 \pm 1.12$ & 0.059 & $4.0 \pm 1.7$ & $4.3 \pm 1.4$ & 0.081 \\
\hline FINS (pmol/l) & $118.4 \pm 37.9$ & $122.6 \pm 46.2$ & 0.071 & $128.6 \pm 45.9$ & $128.5 \pm 52.3$ & 0.914 \\
\hline HOMA-IR & $4.16 \pm 2.45$ & $4.27 \pm 2.67$ & 0.778 & $6.23 \pm 2.12$ & $4.91 \pm 1.34$ & 0.001 \\
\hline HOMA-IS & $91.65 \pm 43.7$ & $81.23 \pm 31.2$ & 0.029 & $101.34 \pm 54.2$ & $80.79 \pm 36.9$ & 0.001 \\
\hline Fasting c peptide (nmol/l) & $1.12 \pm 0.33$ & $1.11 \pm 0.36$ & 0.842 & $1.54 \pm 0.48$ & $1.01 \pm 0.42$ & 0.001 \\
\hline 2-h post-prandial c peptide $(\mathrm{nmol} / \mathrm{l})$ & $2.84 \pm 1.25$ & $2.76 \pm 1.32$ & 0.514 & $2.98 \pm 1.14$ & $2.81 \pm 1.43$ & 0.097 \\
\hline Adiponectin (pg/ml) & $172.1 \pm 40.3$ & $168.12 \pm 29.1$ & 0.845 & $148.5 \pm 37.6$ & $149.12 \pm 29.1$ & 0.843 \\
\hline Resistin (ng/ml) & $6.75 \pm 3.14$ & $6.99 \pm 3.36$ & 0.642 & $12.34 \pm 4.65$ & $11.66 \pm 1.52$ & 0.648 \\
\hline $\mathrm{TNF} \alpha(\mathrm{pg} / \mathrm{ml})$ & $280.13 \pm 121.4$ & $314.25 \pm 76.2$ & 0.025 & $312.79 \pm 119.9$ & $348.5 \pm 125.4$ & 0.045 \\
\hline $\mathrm{CRP}(\mathrm{mg} / \mathrm{l})$ & $4.12 \pm 1.04$ & $4.14 \pm 1.21$ & 0.648 & $5.01 \pm 1.96$ & $4.81 \pm 0.99$ & 0.079 \\
\hline
\end{tabular}

$\mathrm{P}<0.05$ was considered to indicate a statistically significant difference. Values are expressed as the mean \pm standard error of the mean. BMI, body mass index; HbA1c, glycated hemoglobin; FBG, fasting blood glucose; 2hPG, 2-h post-prandial plasma glucose; TG, triglycerides; TC, total cholesterol; H/LDL, high/low-density lipoprotein; CRP, C-reactive protein; TNF, tumor necrosis factor; HOMA, homeostatic model assessment; IR, insulin resistance; IS, insulin sensitivity; FINS, fasting insulin. Values are expressed as the mean \pm standard error of the mean.

and baseline CRP is an important biomarker for the risk of diabetes. High levels of CRP are closely associated with the development of diabetes (27). In the present study, exenatide + MET combination therapy significantly decreased CRP levels $(\mathrm{P}<0.05)$, while BIA30 + MET did not.

TNF- $\alpha$ is a cytokine involved in systemic inflammation and has an important role in the mechanism of insulin resistance associated with obesity. TNF- $\alpha$ has been reported to be widely expressed in adipose tissue (28). In the present study, exenatide + MET combination therapy caused a greater decrease in TNF- $\alpha$ levels than BIA30 + MET combination therapy $(\mathrm{P}<0.05)$.

BIA30 + MET is equal to exenatide + MET regarding HOMA-IS. The patients receiving exenatide + MET combination therapy showed a similarly significant baseline-to-endpoint improvement in $\beta$-cell function to those receiving BIA30 + MET, as evaluated by the HOMA-IS The HOMA-IS index increased from 67.14 \pm 36.4 (baseline) to $91.65 \pm 43.7$ (12 weeks) and from $80.79 \pm 36.9$ (24 weeks) to $92.65 \pm 49.9$ (36 weeks) with exenatide + MET combination therapy $(\mathrm{P}<0.01)$. The HOMA-IS index increased from $66.34 \pm 27.1$ (baseline) to $101.34 \pm 54.2$ (12 weeks) and from $81.23 \pm 31.2$ (24 weeks) to $93.52 \pm 45.6$ (36 weeks) with BIA30 + MET combination therapy $(\mathrm{P}<0.01)$.
Exenatide + MET is superior to BIA30 + MET regarding HOMA-IR. In Phase I, the patients receiving exenatide + MET combination therapy exhibited a significantly greater improvement in $\beta$-cell function than those receiving BIA30 + MET combination therapy, as assessed by HOMA-IR. Furthermore, in Phase III, HOMA-IR was significantly improved in exenatide + MET group, while that in patients receiving BIA30 + MET combination therapy was significantly deteriorated. All of the results suggested that exenatide + MET combination therapy was superior to BIA30 + MET combination therapy regarding its anti-diabetic activities on improving $\beta$-cell function by reducing insulin resistance.

\section{Discussion}

The present study investigated the efficacy of the combination therapy of exenatide or BIA30 and MET in the treatment of overweight or obese patients newly diagnosed with T2DM. The most significant findings were associated with weight reduction, enhanced glycemic control and the reduction in HbA1c values, and showed that the combination therapy of exenatide + MET significantly improved several of the patient's clinical parameters.

The results of the present study suggested that exenatide + MET combination therapy is effective for glucose 
Table IV. Parameter changes in groups A and B in phase III.

\begin{tabular}{|c|c|c|c|c|c|c|}
\hline \multirow[b]{2}{*}{ Parameter } & \multicolumn{3}{|c|}{ Group A } & \multicolumn{3}{|c|}{ Group B } \\
\hline & 24 weeks & 36 weeks & P-value & 24 weeks & 36 weeks & P-value \\
\hline Waist circumference $(\mathrm{cm})$ & $96.2 \pm 11.3$ & $100.2 \pm 10.4$ & 0.021 & $111.4 \pm 13.6$ & $107.2 \pm 11.8$ & 0.021 \\
\hline Weight $(\mathrm{kg})$ & $78.2 \pm 16.3$ & $82.2 \pm 14.9$ & 0.024 & $82.3 \pm 19.6$ & $78.1 \pm 17.2$ & 0.026 \\
\hline $\mathrm{FBG}(\mathrm{mmol} / \mathrm{l})$ & $7.8 \pm 1.2$ & $6.5 \pm 1.5$ & 0.004 & $7.9 \pm 1.1$ & $6.6 \pm 1.5$ & 0.001 \\
\hline 2hPG (mmol/l) & $12.5 \pm 1.1$ & $9.5 \pm 1.7$ & 0.001 & $14.1 \pm 2.4$ & $9.4 \pm 1.2$ & 0.001 \\
\hline HbAlc $(\%)$ & $7.8 \pm 0.6$ & $6.6 \pm 0.8$ & 0.016 & $8.2 \pm 1.5$ & $6.4 \pm 0.8$ & 0.001 \\
\hline $\operatorname{BMI}\left(\mathrm{kg} / \mathrm{m}^{2}\right)$ & $26.1 \pm 1.9$ & $28.1 \pm 2.4$ & 0.009 & $30.1 \pm 3.1$ & $27.5 \pm 1.9$ & 0.004 \\
\hline $\mathrm{TG}(\mathrm{mmol} / \mathrm{l})$ & $1.82 \pm 1.41$ & $1.71 \pm 1.13$ & 0.017 & $2.6 \pm 1.2$ & $1.8 \pm 1.4$ & 0.001 \\
\hline $\mathrm{TC}(\mathrm{mmol} / \mathrm{l})$ & $5.3 \pm 0.7$ & $4.6 \pm 1.2$ & 0.085 & $5.6 \pm 0.6$ & $4.9 \pm 2.1$ & 0.026 \\
\hline HDL (mmol/l) & $1.36 \pm 0.4$ & $1.37 \pm 0.5$ & 0.677 & $1.7 \pm 0.5$ & $1.7 \pm 0.8$ & 0.247 \\
\hline LDL (mmol/l) & $3.61 \pm 1.12$ & $3.53 \pm 1.21$ & 0.845 & $4.3 \pm 1.4$ & $3.7 \pm 1.4$ & 0.0218 \\
\hline FINS (pmol/l) & $122.6 \pm 46.2$ & $137.5 \pm 42.1$ & 0.086 & $128.5 \pm 52.3$ & $126.7 \pm 48.8$ & 0.824 \\
\hline HOMA-IR & $4.27 \pm 2.67$ & $4.84 \pm 1.86$ & 0.043 & $4.91 \pm 1.34$ & $3.97 \pm 1.26$ & 0.015 \\
\hline HOMA-IS & $81.23 \pm 31.2$ & $93.52 \pm 45.6$ & 0.012 & $80.79 \pm 36.9$ & $92.65 \pm 49.9$ & 0.008 \\
\hline Fasting c peptide (nmol/l) & $1.11 \pm 0.36$ & $1.21 \pm 0.36$ & 0.684 & $1.01 \pm 0.42$ & $1.17 \pm 0.51$ & 0.102 \\
\hline 2-h post-prandial c peptide $(\mathrm{nmol} / \mathrm{l})$ & $2.76 \pm 1.32$ & $2.89 \pm 1.42$ & 0.125 & $2.81 \pm 1.43$ & $2.91 \pm 1.12$ & 0.087 \\
\hline Adiponectin (pg/ml) & $168.12 \pm 29.1$ & $178.3 \pm 37.3$ & 0.247 & $149.12 \pm 29.1$ & $227.3 \pm 25.2$ & 0.001 \\
\hline Resistin (ng/ml) & $6.99 \pm 3.36$ & $6.76 \pm 1.44$ & 0.857 & $11.66 \pm 1.52$ & $5.47 \pm 1.31$ & 0.001 \\
\hline $\mathrm{TNF} \alpha(\mathrm{pg} / \mathrm{ml})$ & $314.25 \pm 76.2$ & $271.14 \pm 117.8$ & 0.001 & $348.5 \pm 125.4$ & $231.7 \pm 143.5$ & 0.001 \\
\hline $\mathrm{CRP}(\mathrm{mg} / \mathrm{l})$ & $4.14 \pm 1.21$ & $4.11 \pm 2.01$ & 0.914 & $5.01 \pm 0.99$ & $4.04 \pm 1.21$ & 0.002 \\
\hline
\end{tabular}

$\mathrm{P}<0.05$ was considered to indicate a statistically significant difference. Values are expressed as the mean \pm standard error of the mean. BMI, body mass index; HbA1c, glycated hemoglobin; FBG, fasting blood glucose; 2hPG, 2-h post-prandial plasma glucose; TG, triglycerides; TC, total cholesterol; H/LDL, high/low-density lipoprotein; CRP, C-reactive protein; TNF, tumor necrosis factor; HOMA, homeostatic model assessment; IR, insulin resistance; IS, insulin sensitivity; FINS, fasting insulin. Values are expressed as the mean \pm standard error of the mean.

control in overweight or obese patients newly diagnosed with T2DM. These results have provided additional information, which may enhance the clinical decision-making process for patients who have been unable to achieve appropriate glycemic control. The present study showed that exenatide + MET combination therapy was superior to BIA30 + MET combination therapy for the treatment of overweight or obese patients newly diagnosed with T2DM. It should be taken into account that in the present study, all patients were treated with a combination therapy, whereas only one report demonstrated that a double combination was beneficial for the therapy of T2DM patients (20); however, since the double and combination therapies involve subcutaneous injections of the agents at the same time twice daily and have the potential to favorably affect fasting and post-prandial glucose, they may be considered to be suitable interventions. Exenatide has been shown to improve glycemic control in patients with T2DM who failed to achieve glycemic control with maximally effective MET doses (29). This implied that the shortcomings of MET may be avoided if exenatide is used in the combined therapy model (30).

Consistent with the results of clinical trials with exenatide (19), a significant decrease in body weight was observed in the present study in patients receiving exenatide + MET combination therapy; this decrease was significantly greater than that observed in the patients receiving BIA30 + MET combination therapy. Furthermore, the HbAlc levels were significantly reduced in patients receiving exenatide + MET combination therapy compared with those at baseline; since this decrease was consistent with the reduction in body weight, it was indicated that the observed weight reduction was sufficient to affect glycemic control. Among all of the changing trends between exenatide + MET combination therapy and BIA30 + MET combination therapy, it appeared that the greatest reduction in weight was observed in the patients receiving the combination therapy of exenatide + MET. It should be noted that the long-term implications of the progressive weight reduction observed in the patients treated with exenatide + MET combination therapy, with regard to the glycemic control and overall systemic effects, were not fully elucidated in the present study; however, given the central role of obesity in the pathophysiology of T2DM (31-33), it is suggested that agents that lower blood glucose may reduce this risk factor.

BIA30 has been reported to improve glycemic control in T2DM patients in whom the condition is poorly controlled by other medications (13). BIA30 has been found to be more effective for the treatment of patients with a high baseline HbA1c level, enabling most patients to achieve glycemic control. However, MET is the first-line agent for the treatment of T2DM, particularly in overweight and obese individuals (17). The findings of the present study showed that 
the combination of MET + BIA30 did not improve glycemic control and weight gain was observed in overweight or obese patients newly diagnosed with T2DM subjected to this treatment.

Of note, the present study had a number of limitations due to the lack of control groups treated with placebo or drug monotherapy. All the experiments were omitted mainly considering that most T2DM patients are likely to fail to achieve glycemic control with maximally effective exenatide, MET or BIA30 doses $(14,34,35)$. In future studies using a larger number of patients, placebos may be used as controls.

In conclusion, the present study was the first, to the best of our knowledge, to investigate the use of a combination therapy of Exenatide or BIA30 with MET for overweight or obese patients newly diagnosed with T2MD. Glycemic control was achieved in Group A (exenatide + MET) group. The exenatide + MET combination therapy achieved a significant increase in the level of adiponectin and a significant reduction in the levels of CRP and resistin, while MET + BIA30 did not; furthermore, exenatide + MET caused a significantly greater reduction of TNF- $\alpha$ compared with BIA30 + MET combination therapy $(\mathrm{P}<0.05)$. Exenatide + MET combination treatment therefore provides a potential alternative for the safe and effective treatment of overweight or obese patients newly diagnosed with T2DM.

\section{Acknowledgements}

This study was supported by the Key Science Planning Program of Hainan Province of China (grant nos. ZDXM20120046).

\section{References}

1. Lewis $\mathrm{CP}$ and Newell JN: Patients' perspectives of care for type 2 diabetes in Bangladesh-a qualitative study. BMC Public Health 14: 737, 2014.

2. Wang Y, Zhao L, Huang Q and Peng Y: Effects of dipeptidyl peptidase- 4 inhibitors in a type 2 diabetes patient with failure of glucagon-like peptide-1 receptor agonists. J Diabetes 6: 164-166, 2014.

3. Umpierrez GE and Meneghini L: Reshaping diabetes care: The fundamental role of dipeptidyl peptidase- 4 inhibitors and glucagon-like peptide-1 receptor agonists in clinical practice. Endocr Pract 19: 718-728, 2013.

4. Meier JJ: GLP-1 receptor agonists for individualized treatment of type 2 diabetes mellitus. Nat Rev Endocrinol 8: 728-742, 2012.

5. Bjerre Knudsen L, Madsen LW, Andersen S, Almholt K, de Boer AS, Drucker DJ, Gotfredsen C, Egerod FL, Hegelund AC, Jacobsen $\mathrm{H}$, et al: Glucagon-like Peptide-1 receptor agonists activate rodent thyroid $\mathrm{C}$-cells causing calcitonin release and $\mathrm{C}$-cell proliferation. Endocrinology 151: 1473-1486, 2010.

6. Bunck MC, Diamant M, Cornér A, Eliasson B, Malloy JL, Shaginian RM, Deng W, Kendall DM, Taskinen MR, Smith U, et al: One-year treatment with exenatide improves beta-cell function, compared with insulin glargine, in metformin-treated type 2 diabetic patients: A randomized, controlled trial. Diabetes care 32: 762-768, 2009.

7. Marchetti $P$ and Masini M: Autophagy and the pancreatic beta-cell in human type 2 diabetes. Autophagy 5: 1055-1056, 2009.

8. Rosenstock J, Shenouda SK, Bergenstal RM, Buse JB, Glass LC, Heilmann CR, Kwan AY, MacConell LA and Hoogwerf BJ: Baseline factors associated with glycemic control and weight loss when exenatide twice daily is added to optimized insulin glargine in patients with type 2 diabetes. Diabetes Care 35: 955-958, 2012

9. Anderson ZL and Clements JN: Exenatide extended-release: A once-weekly option for patients with type 2 diabetes. JAAPA 27 : 44-46, 2014.
10. Carrington MJ, Chan YK, Stewart S, Sjouke B, Brazilek R and Cohen N: Long-term tolerance and efficacy of adjunctive exenatide therapy on glycaemic control and bodyweight in type 2 diabetes: A retrospective study from a specialist diabetes outpatient clinic. Intern Med J 44: 345-353, 2014.

11. Shao N, Kuang HY, Hao M, Gao XY, Lin WJ and Zou W: Benefits of exenatide on obesity and non-alcoholic fatty liver disease with elevated liver enzymes in patients with type 2 diabetes. Diabetes Metab Res Rev 30: 521-529, 2014.

12. Abdul-Ghani MA, Puckett C, Triplitt C, Maggs D, Adams J, Cersosimo $\mathrm{E}$ and DeFronzo RA: Initial combination therapy with metformin, pioglitazone and exenatide is more effective than sequential add-on therapy in subjects with new-onset diabetes. Results from the efficacy and durability of initial combination therapy for type 2 diabetes (EDICT): A randomized trial. Diabetes Obes Metab 17: 268-275, 2015.

13. Almansari A, Khader S, Kharawagh A, AbdelFattah W and Badawy T: Safety and efficacy of biphasic insulin aspart 30 in type 2 diabetes patients switched from either biphasic or basal human insulin: Results from the Gulf cohort of the A1 chieve study. Int J Clin Pract 68: 850-856, 2014.

14. Bergenstal R, Lewin A, Bailey T, Chang D, Gylvin T and Roberts V; NovoLog Mix-vs.-Exenatide Study Group: Efficacy and safety of biphasic insulin aspart 70/30 versus exenatide in subjects with type 2 diabetes failing to achieve glycemic control with metformin and a sulfonylurea. Curr Med Res Opin 25: 65-75, 2009.

15. Yang WY, Ji QH, Zhu DL, Yang JK, Chen LL, Liu ZM, Yu DM and Yan L: Thrice-daily biphasic insulin aspart 30 may be another therapeutic option for Chinese patients with type 2 diabetes inadequately controlled with oral antidiabetic agents. Chin Med J (Engl) 122: 1704-1708, 2009.

16. Davidson JA, Liebl A, Christiansen JS, Fulcher G, Ligthelm RJ, Brown P, Gylvin T and Kawamori R: Risk for nocturnal hypoglycemia with biphasic insulin aspart 30 compared with biphasic human insulin 30 in adults with type 2 diabetes mellitus: A meta-analysis. Clin Ther 31: 1641-1651, 2009.

17. American Diabetes Association: Standards of medical care in diabetes-2009. Diabetes Care 32 (Suppl 1): S13-S61, 2009.

18. Kim SW: Triple combination therapy using metformin, thiazolidinedione and a GLP-1 analog or DPP-IV inhibitor in patients with type 2 diabetes mellitus. Korean Diabetes J 34: 331-337, 2010.

19. Derosa G, Franzetti IG, Querci F, Carbone A, Ciccarelli L, Piccinni MN, Fogari E and Maffioli P: Exenatide plus metformin compared with metformin alone on $\beta$-cell function in patients with Type 2 diabetes. Diabet Med 29: 1515-1523, 2012.

20. Kann PH, Wascher T, Zackova V, Moeller J, Medding J, Szocs A, Mokan M, Mrevlje F and Regulski M: Starting insulin therapy in type 2 diabetes: Twice-daily biphasic insulin Aspart 30 plus metformin versus once-daily insulin glargine plus glimepiride. Exp Clin Endocrinol Diabetes 114: 527-532, 2006.

21. General Assembly of the World Medical Association: World medical association declaration of Helsinki: Ethical principles for medical research involving human subjects. J Am Coll Dent 81: 14-18, 2014.

22. Engelgau MM, Thompson TJ, Herman WH, Boyle JP, Aubert RE, Kenny SJ, Badran A, Sous ES and Ali MA: Comparison of fasting and 2-hour glucose and HbA1c levels for diagnosing diabetes. Diagnostic criteria and performance revisited. Diabetes Care 20: 785-791, 1997.

23. Friedewald WT, Levy RI and Fredrickson DS: Estimation of the concentration of low-density lipoprotein cholesterol in plasma, without use of the preparative ultracentrifuge. Clin Chem 18: 499-502, 1972.

24. Steppan CM, Bailey ST, Bhat S, Brown EJ, Banerjee RR, Wright CM, Patel HR, Ahima RS and Lazar MA: The hormone resistin links obesity to diabetes. Nature 409: 307-312, 2001.

25. Yamamoto H, Maeda K, Uji Y, Tsuchihashi H, Mori T, Shimizu T, Endo Y, Kadota A, Miura K, Koga Y, et al: Association between reduction of plasma adiponectin levels and risk of bacterial infection after gastric cancer surgery. PloS One 8: e56129, 2013.

26. Shehzad A, Iqbal W, Shehzad O and Lee YS: Adiponectin: Regulation of its production and its role in human diseases. Hormones (Athens) 11: 8-20, 2012.

27. Freeman DJ, Norrie J, Caslake MJ, Gaw A, Ford I, Lowe GD, O'Reilly DS, Packard CJ and Sattar N; West of Scotland Coronary Prevention Study: C-reactive protein is an independent predictor of risk for the development of diabetes in the West of Scotland coronary prevention study. Diabetes 51: 1596-1600, 2002. 
28. Xu H, Uysal KT, Becherer JD, Arner P and Hotamisligil GS Altered tumor necrosis factor-alpha (TNF-alpha) processing in adipocytes and increased expression of transmembrane TNF-alpha in obesity. Diabetes 51: 1876-1883, 2002.

29. DeFronzo RA, Ratner RE, Han J, Kim DD, Fineman MS and Baron AD: Effects of exenatide (exendin-4) on glycemic control and weight over 30 weeks in metformin-treated patients with type 2 diabetes. Diabetes Care 28: 1092-1100, 2005.

30. Frias JP, Guja C, Hardy E, Ahmed A, Dong F, Öhman P and Jabbour SA: Exenatide once weekly plus dapagliflozin once daily versus exenatide or dapagliflozin alone in patients with type 2 diabetes inadequately controlled with metformin monotherapy (DURATION-8): A 28 week, multicentre, double-blind, phase 3, randomised controlled trial. Lancet Diabetes Endocrinol 4: 1004-1016, 2016

31. Mohammadzadeh G and Zarghami N: Hypoadiponectinemia in obese subjects with type II diabetes: A close association with central obesity indices. J Res Med Sci 16: 713-723, 2011.
32. Vimaleswaran KS, Radha V, Ramya K, Babu HN, Savitha N, Roopa V, Monalisa D, Deepa R, Ghosh S, Majumder PP, et al: A novel association of a polymorphism in the first intron of adiponectin gene with type 2 diabetes, obesity and hypoadiponectinemia in Asian Indians. Human Genet 123: 599-605, 2008.

33. Weyer C, Funahashi T, Tanaka S, Hotta K, Matsuzawa Y, Pratley RE and Tataranni PA: Hypoadiponectinemia in obesity and type 2 diabetes: Close association with insulin resistance and hyperinsulinemia. J Clin Endocrinol Metab 86: 1930-1935, 2001.

34. Weise WJ, Sivanandy MS, Block CA and Comi RJ: Exenatide-associated ischemic renal failure. Diabetes Care 32: e22-e23, 2009.

35. Barnett AH, Burger J, Johns D, Brodows R, Kendall DM, Roberts A and Trautmann ME: Tolerability and efficacy of exenatide and titrated insulin glargine in adult patients with type 2 diabetes previously uncontrolled with metformin or a sulfonylurea: A multinational, randomized, open-label, two-period, crossover noninferiority trial. Clin Ther 29: 2333-2348, 2007. 